\title{
Serum Levels of Tumor Necrosis Factor Alpha in Chronic Schizophrenic Versus Healthy Control and Correlation with Severity of Illness
}

\author{
Rona Hanani Simamora ${ }^{1}$, Bahagia Loebis ${ }^{2}$ \\ Department of Psychiatry \\ Medical Faculty, University of Sumatera Utara \\ Medan, Sumatera Utara, Indonesia \\ rona.hanani@gmail.com, bahagia8loebis@gmail.com
}

\begin{abstract}
Schizophrenia is a common psychotic disorder, with a risk of about $1 \%$, the aetiology of schizophrenia unknown, one of which includes immunological disorders. Although, there are conflicting results, most studies focusing on plasma levels or the production of mitogen-stimulated cytokines, such as tumor necrosis factor. This study compared serum levels of Tumor necrosis factor alpha in male chronic schizophrenic patients and healthy control, and the correlation with severity of illness. This study was conducted on $\mathbf{4 0}$ male patients diagnosed with chronic schizophrenic and 40 healthy control. Severity illness was assessed with Positive and Negative Syndrome Scale. Serum levels of Tumor necrosis factor alpha were measured by immunossay. Tumor necrosis factor alpha levels were significantly higher in male patients with chronic schizophrenic to healthy control subjects. Correlation analysis revealed a significant positive correlation between the serum levels of Tumor necrosis factor alpha and the Positive and Negative Syndrome Scale total score. This study suggest that Tumor necrosis factor alpha may be involved in the psychopathology of schizophrenia and may be a marker of schizophrenia.
\end{abstract}

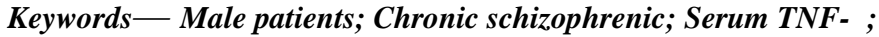
Healthy control; Severity of illness

\section{INTRODUCTION}

Schizophrenia is a common psychotic disorder, with a risk of about $1 \%$, the most common early onset of this disease is 15-30 years of age, and is a chronic disease that causes disruption to patients and their families [1]. The exact cause of schizophrenia is not known, although several aetiological theories have been proposed for the disease, including developmental or neurodegenerative processes, neurotransmitter abnormalities, viral infection and immune dysfunction or autoimmune mechanisms [2]. Schizophrenic patients have aberrant proportions of immuno-competent cells and varied levels of cytokines, especially proinflammatory interleukin (IL)-6, IL-1 and tumour necrosis factor (TNF)- $\alpha$, in their peripheral blood or cerebrospinal fluid [3]. Cytokines function as chemical messengers between immune cells and have numerous important functions in immune regulation. They also play a critical role in infectious and inflammatory processes by mediating the cross-talk between the brain and the immune system, which has been a recent focus of immunologic research in schizophrenia [4]. TNF- $\alpha$ production by schizophrenic patients was significantly higher than by normal controls [5,6]. In contrast to study conducted by $\mathrm{Lv}$ in Beijing in 2012 reported that TNF- $\alpha$ levels were significantly lower in patients with chronic schizophrenia relative to healthy control subjects $(\mathrm{p}<0.01)$. Correlation analysis revealed a significant negative correlation between the TNF- $\alpha$ levels and the PANSS total score $(p<0.01)$ [7]. Therefore, this study is interested to determine whether there are differences in serum TNF- $\alpha$ in male patients with chronic schizophrenic and healthy control and correlation with severity illness.

\section{METHODS}

\section{A. Data Source and sample}

This study was an unpaired numerical comparative analysis, used cross-sectional study, divided in two groups: male patients with chronic schizophrenic and healthy control group and the correlation with severity illness. Among psychiatric patients admitted in wards of the Prof. Dr. M. Ildrem Hospital, North Sumatera, Indonesia, during September 2016 to February 2017, we recruited fourty schizophrenic patients. All patients had chronic schizophrenic patients in stabilization phase of treatment at the time of study enrollment. All patients had been medication risperidone $4 \mathrm{mg}$, heavy smokers, age 2040 years old, Body Mass Index (BMI) score 18.50 - 24.99 $\mathrm{kg} / \mathrm{m} 2$, understand the Indonesian language and willing to be a respondent and can be interviewed. Patients with a history of any concomitant psychiatric illness, such as substance or alcohol abuse, a history of chronic and acute physical condition (such as infectious or allergic diseases) associated with abnormal cell-mediated immunity or a known autoimmune disease were excluded. Fourty controls were recruited at the same hospital in the same hospital among employees, nurses and other medical personnel who working there and caregivers who come to check-up their families. Age, heavy smokers and Body Mass Index (BMI) were matched between schizophrenia patients and healthy controls. Each healthy control with any personal or familial history of psychiatric illness, diagnosed 
autoimmune disease, chronic and acute physical illness (such as infectious or allergic diseases) associated with abnormal cell-mediated immunity, or substance or alcohol abuse were excluded. The patients gave informed consent after the procedure had been fully explained. This study was approved by the Institutional Ethical Committee of University of Sumatera Utara.

\section{B. Measures}

Male who reported having been diagnosed with chronic schizophrenic by a psychiatrist; therefore, for the purposes of this study, the definition of schizophrenic is a chronic schizophrenic patient in the stabilization phase of treatment [8,9]. Schizophrenic patients assessed by using International Statistical Classification of Diseases and Related Health Problems - 10 (ICD-10) [10].

The severity of illness was assessed using the Positive and Negative Syndrome Scale (PANSS), that is determined from the total scores PANSS to reflect burden of illness [11].

Tumor necrosis factor alpha (TNF $-\alpha$ ) also known as cachectin, is the prototypic ligand of the TNF superfamily. It is a pleiotropic molecule that plays a central role in inflammation, immune system development, apoptosis, and lipid metabolism. In this study, serum TNF $\alpha$ levels were measured by Quantikine HS Human TNF- $\alpha$ Immunoassay which is a 6.5 hour solid phase ELISA designed to measure TNF- $\alpha$ in serum and plasma [12].

\section{Covariates}

Sociodemographic characteristics included age, marital status was coded into two catogories (Married or Unmarried), educational level education was categorized as junior high school, senior high school, and college, and ethnic group was categorized Bataknese or Non Bataknese. Chronic and acute physical condition assessed by the health interview (such as infectious or allergic diseases). Heavy smokers was defined status of smoking exposure (>20 cigarettes daily) [13]. Body mass Index (BMI) was calculated using measurements of subjects weight and height [weight $(\mathrm{kg}) /$ height $\left(\mathrm{m}^{2}\right)$ ]. Normal was considered present if subjects had a BMI of $18.50-24,99$ $\mathrm{kg} / \mathrm{m}^{2}[14]$.

\section{Statistical Analysis}

Serum levels of $\mathrm{TNF}-\alpha \mathrm{s}$ in both groups were analyzed using unpaired $\mathrm{T}$ test, If the serum levels of TNF- $\alpha$ were normally distributed both in schizophrenic patients and controls (Saphiro-Wilk test, $\mathrm{p}>0.05$ ). The significance level was set at $\mathrm{p}<0.05$ for all analysis. The correlation of serum levels of TNF- $\alpha$ with severity of illness was analyzed by using Pearson correlation test with the condition that the data for both serum levels of TNF- $\alpha$ variables and the total PANSS score were normally distributed, If not normally distributed, data will be analyzed by using Spearman correlation test [15].

\section{RESULTS}

\section{A. Sociodemographic Characteristics}

In this study recruiting 80 male subjects, and divided into two groups: 40 subject had been diagnosed with chronic schizophrenic by psychiatrist, And 40 subjects as healthy control group. The mean age in the schizophrenic group

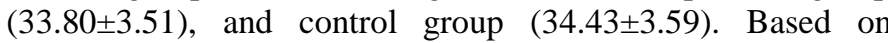
marital status, the schizophrenic group married $27(21.60 \%)$ more than unmarried subjects, and healthy control group the most was married subject $24(19.20 \%)$. In both the schizophrenic group and healthy control group the most was Bataknese ethnic group. The mean body mass index in the schizophrenic group was 21.61 \pm 2.01 , and healthy control group was $21.13 \pm 1.86$. There were no significant differences in age, marital status, ethnic group, and BMI between the groups (both $\mathrm{p}>0.05$ ).

In schizophrenic group, highest level of education is junior high school $(47.50 \%)$ and in healthy group is collage $(42.50 \%)$. There were significant differences in education $(\mathrm{p}<0.05)$, but education did not significantly affect of serum levels of TNF- $\alpha$.

TABLE I

DEMOGRAPHIC CHARACTERISTIC OF THE SAMPLES ACCORDING TO THE GROUP

\begin{tabular}{|l|l|l|l|}
\hline \multirow{2}{*}{ Variable } & \multicolumn{3}{|c|}{ Group } \\
\cline { 2 - 4 } & Schizophrenic & Control & p-value \\
\hline Age & $33.80 \pm 3.51$ & $34.43 \pm 3.59$ & $0.433^{\mathrm{a}}$ \\
\hline $\begin{array}{l}\text { Marital Status } \\
\text { Married }\end{array}$ & $13.00(10.40)$ & $16.00(12.80)$ & $0.845^{\mathrm{b}}$ \\
Unmarried & $27.00(21.60)$ & $24.00(19.20)$ & \\
\hline Education & & & \\
Junior high & $15.00(37.50)$ & $8.00(20.00)$ & \\
Senior high & $15.00(37.50)$ & $15.00(37.50)$ & $0.008^{\mathrm{b}}$ \\
College & $6.00(15.00)$ & $17.00(42.50)$ & \\
\hline Ethnic group & & & \\
Bataknese & $25.00(62.50)$ & $28.00(70.00)$ & $0.478^{\mathrm{b}}$ \\
Non Bataknese & $15.00(37.50)$ & $12.00(30.00)$ & \\
\hline Body Mass Index & $21.61 \pm 2.01$ & $21.13 \pm 1.86$ & $0.299^{\mathrm{c}}$ \\
\hline
\end{tabular}

${ }^{a}$ Independen T test,${ }^{\mathrm{b}}$ Chi Square, ${ }^{\mathrm{c}}$ Mann Whitney U test

B. Comparison Serum Levels of Tumor Necrosis Factor Alpha $(T N F-\alpha)$ in Male Patients with Chronic Schizophrenic Versus Healthy Control

All Serum levels of TNF- $\alpha$ in male patients with chronic schizophrenic $(25.12 \pm 1.76)$ was significantly higher than healthy controls group $(5.48 \pm 1.68)$, by using independent $\mathrm{T}$ test, there were significant difference between the mean TNF$\alpha$ between the schizophrenic and healthy control groups $(\mathrm{p}=0.001 ; \mathrm{p}<0.05)$.

TABLE III

DEMOGRAPHIC CHARACTERISTIC OF THE SAMPLES ACCORDING TO THE GROUP

\begin{tabular}{|l|l|l|l|}
\hline Variable & $\begin{array}{l}\text { TNF- } \alpha \\
\text { serum level } \\
(\text { mean } \pm \text { s.d) }\end{array}$ & $\begin{array}{l}\text { Mean Difference } \\
\text { (95\% Confidence } \\
\text { Interval) }\end{array}$ & p-value \\
\hline $\begin{array}{l}\text { Chronic } \\
\text { Schizophrenic }\end{array}$ & $25.12 \pm 1.76$ & $19.63(18.8620 .40)$ & $0.001 *$ \\
\cline { 1 - 2 } Healthy Control & $5.49 \pm 1.69$ & & *Independen T test \\
\hline
\end{tabular}


C. Correlations between Serum Levels of Tumor Necrosis Factor Alpha (TNF- $\alpha)$ and Severity of Illness in Schizophrenia

The correlation of serum levels of TNF- $\alpha$ with severity of the disease was analyzed using Spearman correlation test, because for both serum levels of TNF- $\alpha$ variables and the total PANSS score were not normally distributed. Serum levels of TNF- $\alpha$ were significantly positively correlated with the PANSS total score $(r=0.723, \mathrm{p}<0.001, \mathrm{n}=40)$.

TABLE IIIII

CORRELATIONS BETWEEN SERUM LEVELS OF TNF-ALPHA AND SEVERITY ILLNESS IN SCHIZOPHRENIA

\begin{tabular}{|l|l|}
\hline \multicolumn{1}{|c|}{ Total PANSS Score } \\
\hline Serum Levels of TNF- $\alpha$ & $\begin{array}{l}\mathrm{r}=0.723 \\
\mathrm{p}<0.001 \\
\mathrm{n}=40\end{array}$ \\
\hline
\end{tabular}

\section{IV.DISCUSSION}

The main findings of the present study were that serum levels of TNF- $\alpha$ level was significantly higher in male patients with chronic schizophrenia than in healthy control subjects, and there were significantly positive correlations between serum levels of TNF- $\alpha$ and the total PANSS score. We demonstrated that pro inflammatory cytokines TNF- $\alpha$ were significantly higher in schizophrenic patients as compared to healthy controls. These results are consistent with some previous studies that showed higher production of TNF- $\alpha$ levels in schizophrenic patients. Miller et al. and Potvin et al. reported that Increation of serum levels of TNF- $\alpha$ alpha is reciprocal with the well-described pro-inflammatory state in schizophrenia. Increased TNF- $\alpha$ are proinflammatory mediators produced predominantly by macrophages $[16,17]$. Several studies have proved increased plasma cytokine levels or mitogen-stimulated cytokine production in schizophrenia such as TNF- $\alpha$ [18].

Increased plasma levels of TNF associated with schizophrenia is also confirmed by $\mathrm{Na}$ et al. in Korea and Theodoropoulou et al. in Athens shows the levels of TNF- $\alpha$ were significantly higher in chronic schizophrenic patients compared with healthy controls ( $p<0.001)$. [5,6] Kubistova et al. measuring elevated serum levels of TNF- $\alpha$ in schizophrenic and healthy controls pre and post treatment found significant differences in serum levels of TNF- $\alpha$ were higher in the schizophrenic group compared with controls both before and after treatment. significant correlation between PANSS subscales for positive and negative subscales and the total PANSS score or between the differences in psychopathology and cytokine levels before and after treatment [19]. Al- Asmari observed serum levels of TNF- $\alpha$ of schizophrenic patients were significantly higher than those of healthy controls. The different activities of inflammatory cytokines in schizophrenic patients suggest that specific subtypes of cytokines, monocytic proinflammatory cytokines,may be associated with the immunopathogenesis of schizophrenia [20]. Ajami et al. reported serum levels TNF- $\alpha$ in schizophrenic higher than healthy control. They concluded an increase in TNF- $\alpha$ may have an important role in schizophrenic psychopathology [21].

In contrast with Zhang et al. measuring cytokine levels including TNF- $\alpha$ in chronic schizophrenic patients who smoked with long-term antipsychotic use found no significant difference in serum levels of TNF- $\alpha$ in chronic schizophrenic patients who smoked $(10.1 \pm 1.8)$ and non smoke $(10.7 \pm 2.7)$ $\mathrm{p}=0.28$. Nevertheless they argue in accordance with previous studies that schizophrenia is characterized by activation of proinflammatory cytokines such as TNF- $\alpha$ [22]. TNF- $\alpha$ is a cytokine involved in systemic inflammation and is a member of a group of cytokines which stimulate acute phase reactions . A chronic immune activation in schizophrenia have been shown elsewhere [23]. TNF- $\alpha$ is a ubiquitous pro-inflammatory cytokine elevated in immune response. TNF- $\alpha$ might contribute to the pathogenesis of schizophrenia by activation of the hypothalamo-pituitary-adrenocortical (HPA) axis, activation of neuronal serotonin transporters, stimulation of the indoleamine 2,3-dioxygenase which leads to tryptophan depletion and activation of kynurenine metabolites, or by neurotoxic release of glutamate [24]. In addition, cytokines might cross the blood-brain barrier (BBB) either through leaky areas or by active transport. Increased permeability of the BBB may enable activated immune or neurotoxic cytokines to enter the CNS and trigger psychopathological changes [20].

\section{CONCLUSIONS}

This study suggest that TNF- $\alpha$ maybe play important roles in the pathophysiology of schizophrenia and may be a marker of schizophrenia. There is a growing evidence base supporting the role of inflammation in the etiology of schizophrenia. TNF$\alpha$ might contribute to the pathogenesis of schizophrenia by activation of the HPA axis, activation of neuronal serotonin transporters, stimulation of the indoleamine 2,3-dioxygenase which leads to tryptophan depletion and activation of kynurenine metabolites, or by neurotoxic release of glutamate and cytokines might cross the blood-brain barrier (BBB). Although, many studies report immunological findings in schizophrenia but are still often contradictory. Variables that may be confounding in studies are important for control, including disease length, treatment received, comorbidities and additional factors that may be biased variables. So the evidence that changes in cytokine levels occur in schizophrenia is still needed.

\section{ACKNOWLEDGMENT}

Authors who wishing to thank the infinite thanks for help or encouragement from supervisors, resident colleagues, all technical staff, and families who have provided moral and material support so that this paper can be completed.

\section{REFERENCES}

[1] B. J. Sadock AND V. A. Sadock. Kaplan \& Sadock's Synopsis Of Psychiatry Behavioral Sciences/ Clinical Psychiatry, 11th ed., Philladelphia: Lippincott williams \& wilkins, 2015.

[2] M. Reale, A. Patruno, M. A. De Lutiis, M. Pesce, M. Felaco , and M. Di Giannantonio, "Dysregulation of chemo-cytokine production in 
schizophrenic patients versus healthy controls," BMC neuroscience.,vol. 12(13),pp. 1-9, January. 2011.

[3] A. B. Erbagci , H. Herken, O. Koyluoglu, N. Yilmaz, and M. Tarakcioglu, "Serum IL-1b, sIL-2R, IL-6, IL-8 and TNF- $\alpha$ in schizophrenic patients relation with symptomatology and responsiveness to risperidone treatment." Mediators of inflammation., vol. 10,pp. 109-115, June. 2001.

[4] A. C. Altamura, M. Buoli, and S. Pozzoli, "Role of immunological factors in the pathophysiology and diagnosis of bipolar disorder: comparison with schizophrenia," Psychiatry Clin Neurosci ., vol. 68(1),pp. 21-36, January. 2014.

[5] K. S. Na and Y. K. Kim.. "Monocytic, Th1 and Th2 cytokine alterations in the pathophysiology of schizophrenia." Neuropsychobiology; vol. 56,pp. 55-63, November. 2007.

[6] S. Theodoropoulou, G. Spanakos, C. N. Baxevanis, M. Economou, A. D. Gritzapis, and M. P. Papamichail, et.al, "Cytokine serum levels, autologous mixed lymphocyte reaction and surface marker analysis in never medicated and chronically medicated schizophrenic patients. Schizophrenia research," vol. 47,pp. 13-25. January. 2001.

[7] M. H. Lv, Y. L. Tan, S. X. Yan, L. Tian L, D. C. Chen, and S. P. Tan, et al, "Decreased serum TNF-alpha levels in chronic schizophrenia patients on long-term antipsychotics: correlation with psychopathology and cognition," Psychopharmacology., vol. 232,pp. 165-172, June. 2015 .

[8] M. R. Iriondo, K. Salaberria, and E. Echeburua, "Schizophrenia. Analysis and psychological treatment according to the clinical staging," Actas Esp Psiquiatr., vol. 41(1),pp. 52-9, 2013.

[9] J. M. Kane, T. S. Stroup, and S. R. Marder, Schizophrenia: Pharmacological Treatment, 9th ed. B. J. Sadock, V.A. Sadock, and P. Ruiz P, Ed., in Kaplan \& Sadock's comprehencive text book of psychiatry. Philadelphia: Lippincott Williams \& Wilkins, 2003.

[10] World Health Organization, "The ICD-10 classification of mental and behavioural disorders, clinical descriptions and diagnostic guidelines." 2016.

[11] R. Salan, R. Budiman, and T. K. Bastaman, "The Positive and Negative Syndrome Scale (PANSS) in Indonesia : A Validation and Reliability Study of the on Schizophrenics," Department of Neuropsychiatry Faculty of Medicine, Indonesia University, vol. 28(3),pp. 1-23, 1995.

[12] R\&D systems, Inc. Quantikine HS human TNF- $\alpha$ immunoassay kit, 2016.

[13] W. J. Yun, M. H. Shin, S. S. Kweon, S. Y. Ryu, and J. A. Rhee, "Association of smoking status, cumulative smoking, duration of smoking cessation, age of starting smoking, and depression in korean adults," BMC public Health, vol. ;17(724),pp. 1-7. 2012.
[14] Departement of health and human services centers for disease control and prevention. (2016) Body mass index: Consideration for practitioners. bolton naturopahatic clinic. [Online]. Available at: http://www.cdc.gov/obesity/downloads/BMIforPactitioners.pdf.ca.

[15] S. M. Dahlan, "Statistik untuk kedokteran dan kesehatan deskriptif. bivariat dan multivariat dilengkapi aplikasi menggunakan SPSS. 6th ed. Jakarta: Epidemiologi Indonesia, 2016.

[16] B. J. Miller, P. Buckley, W. Seabolt, A Mellor, and B. Kirkpatrick, "Meta-Analysis of Cytokine Alterations in Schizophrenia: Clinical Status and Antipsychotic Effects," Biol Psychiatry., vol 70(7),pp. 663671, October. 2011

[17] S. Potvin, E. Stip, A. A. Sepehry, A. Gendron, R. Bah, and E. Kouassi, "Inflammatory cytokine alterations in schizophrenia: a systematic quantitative review," Biol. Psychiatry., vol. 63,pp. 801-808, April. 2008.

[18] S. H. Chang, S. Y. Chiang C. C. Chiu, C. C. Tsai, H. H. Tsai, and C. Y. Huang, "Expression of anti-cardiolipin antibodies and inflammatory associated factors in patients with schizophrenia," Psychiatry Res., vol. 187,pp. 341-6, May. 2011.

[19] A. Kubistova, J. Horacek, and T. Novak, "Increased interleukin-6 and tumor necrosis factor alpha in first episode schizophrenia patients versus healthy control," Psychiatria danubina., vol. 24(1),pp. 153-156, September. 2012

[20] A. Al-Asmari and M. W. Khan, "Inflammation and schizophrenia: alterations in cytokine levels and perturbation in antioxidative defense systems," Human and experimental toxicolog., vol. 33(2),pp. 115-122, February. 2014

[21] A. Ajami, F. Abedian, S. H. Hosseini, E. Akbarian, R. A. Navaei, and M Taghipour, "Serum TNF-alpha, IL-10 and IL-2 in schizophrenic patients before and after treatment with risperidone and clozapine," $J$. Immunol., vol. 11(3),pp. 200-209, September. 2014.

[22] X. Y. Zhang, L. Y. Cao, C. Song, G. Y. Wu, D. C. Chen, and L. Y. Qi , et al., "Lower serum cytokine levels in smokers than nonsmokers with chronic schizophrenia on long-term treatment with antipsychotics," Psychophamacology., vol. 201(3),pp. 383-389, December. 2008.

[23] L. P. Francesconia, K. M. Cereserb, R. Mascarenhasa, L. Stertzc, C. S. Gamab, and P. B. De-Abreua, "Increased annexin-v and decreased tnfalpha serum levels in chronic-medicated patients with schizophrenia," Neuroscience letter., vol. 502, pp. 143-146, June. 2011.

[24] H. Himmerich, M. Berthold-Losleben, T. Pollmacher T, "The relevance of the TNF-alpha system in psychiatric disorders," Fortschr. Neurol. Psychiatry., vol. 77,pp. 334-335, May. 2009. 